\title{
Cellulose-Supported Metal Nanocomposite as a Green and Reusable Catalyst for One-Pot Multicomponent Synthesis of 2-Amino-4H-Chromene
}

\section{Derivatives}

\author{
Mohammad Farhadnia, Shahrzad Javanshir* \\ Department of Chemistry, Iran University of Science \& Technology, Tehran 16846-13114, Iran \\ E-mail: shjavan@iust.ac.ir
}

\begin{abstract}
A simple and convenient approach for the synthesis of 2-amino-4H-chromene derivatives has been developed via a multicomponent reaction, which involves the condensation of 1,3-dicarbonyls compounds, aromatic aldehydes and malononitrile using cellulose-supported metal nanocomposite as a green, reusable and environmentally benign catalyst system. Environmental friendly, recyclability, cost-effectiveness, easy workup and excellent yields are the major attributes of this one-pot procedure.
\end{abstract}

Keywords: 2-amino-4H-chromenes, multicomponent reaction, nanocomposite.

\section{Introduction}

Multicomponent reactions (MCRs), an important subclass of tandem reactions, are onepot processes in which three or more accessible components react to form a single product that incorporates essentially most or all atoms of the reactants used [1]. One-pot multicomponent strategies grant remarkable advantages over conventional bimolecular reactions owing to their convergence, atom-economy, operational simplicity, structural diversity and shortness of the synthetic pathway [2]. MCRs have recently gained a new 
dimension in the field of designing methods to produce elaborate libraries of biologically active compounds. The fusion of biodynamic hetero systems has emerged as a useful tool for the design of new molecular frameworks for potential drugs with diverse pharmacological activities [3].

4H-Chromene and its derivatives are biologically interesting compounds known for their antimicrobial and antifungal, antioxidant, antitumor, hypotensive, anti-proliferation, local anesthetic, antiallergenic and anti HIV. Besides, 4H-chromenes can be employed as cosmetics or pigments, and useful as photoactive materials. Due to the important aforementioned properties of chromene derivatives, considerable attention has been focused on the development of environmentally friendly methodologies to synthesize 2 -amino- $4 \mathrm{H}$ chromene scaffold [4].

Recent catalytic systems for MCR synthesis of 2-amino- $4 H$-chromene derivatives consist of homogeneous or heterogeneous $\mathrm{TiCl}_{4}$ [5a], $\mathrm{Fe}(\mathrm{HSO} 4)_{3}[5 \mathrm{~b}], \mathrm{MeSO}_{3} \mathrm{H}$ [5c], nano-sized zeolite clinoptilolite [5d], tungstic acid functionalized mesoporous SBA-15 [5e], nano-sized $\mathrm{CoFe}_{2} \mathrm{O}_{4}$ [6a], $\mathrm{CuO}-\mathrm{CeO}_{2}$ [6b], Mg/Al hydrotalcite [6c-d], Alumina [6e], L-proline [7a], chitosan [7b], 4-dimethylaminopyridine [7c], morpholine [7d], different tetraalkylammonium halides [8] or an enzyme such as lipase [9]. Therefore, the search of improved catalysts for the synthesis of 2 -amino- $4 H$-chromene derivatives using an eco-friendly approach is of prime importance. Development of efficient and practical catalysts for organic synthesis is of considerable interest to both academia and industries.

In this regard, cellulose -supported metal nanocomposite possesses unique features such as environmental compatibility, non-toxicity, reusability, non-corrosively, chemical and physical stability and can be used over a prolonged duration of time.

As a part of our continuing efforts in laboratory towards the development of clean and environmentally benign methodologies for organic reactions [10], herein, we decided to use 
cellulose-supported metal nanocomposite for the mild and highly efficient three-component synthesis of 2-amino- $4 H$-chromene derivatives via a domino Knoevenagel-Michael condensation reaction of 1, 3-dicarbonyls compounds, aromatic aldehydes and malononitrile (Scheme 1).
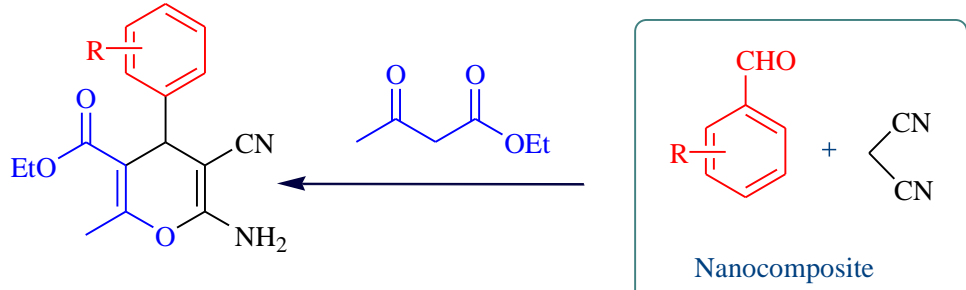

Ethanol, $50{ }^{\circ} \mathrm{C}$

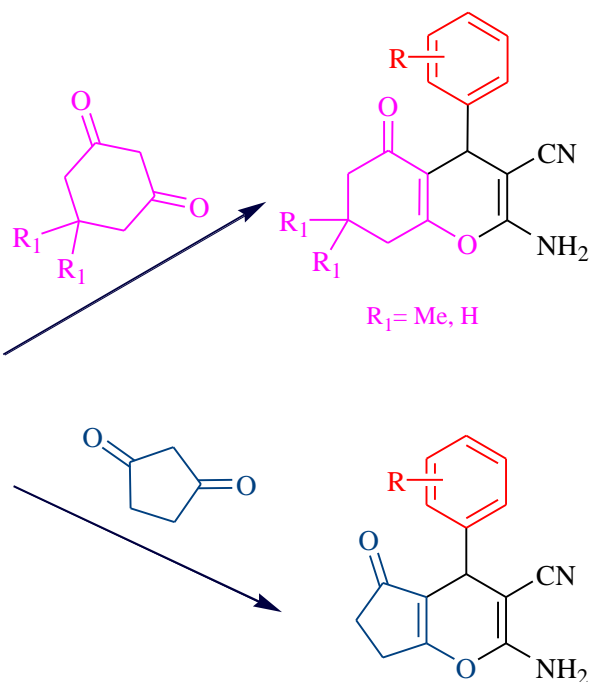

Scheme 1. Three-component reaction of different enols with aromatic aldehydes and malononitrile.

\section{Experimental}

\section{Materials and methods}

All commercially available chemicals were obtained from Merck and Aldrich, and used without further purifications, except for benzaldehyde, which was used as a fresh distilled sample. All reactions and the purity of 2 -amino- $4 H$-chromene derivatives were monitored by thin-layer chromatography (TLC) using aluminum plates coated with silica gel F254 plates (Merck) using ethyl acetate and $n$-hexane as eluents. The spots were detected either under UV light or by placing in an iodine chamber. Melting points were determined in open capillaries using an Electrothermal 9100 instrument. IR spectra were recorded on a Shimadzu FT-IR400s. ${ }^{1} \mathrm{H}$ NMR spectra were recorded on an Avance Bruker DRX-300 MHz. 
General procedure for the synthesis of 2-amino-4H-chromene derivatives

A $10 \mathrm{~mL}$ round-bottom flask was filled with aromatic aldehydes $1(1 \mathrm{mmol})$, malononitrile

2 (1 mmol), 1,3-dicarbonyls compounds 3, 6 (1 mmol), and cellulose-supported metal nanocomposite $(20 \mathrm{mg})$. The reaction mixture was then stirred at $50{ }^{\circ} \mathrm{C}$ until the reaction was completed. The progress of the reaction was monitored by TLC. Upon completion of the reaction, the catalyst was removed so simple then washed with acetone and after drying could be ready to use for the next reaction without loss in activity. The precipitated were separated by filtration and washed thoroughly with ethylacetat to afford the product. If necessary, simple recrystallization was carried out in $\mathrm{EtOH} / \mathrm{H}_{2} \mathrm{O}$.

\section{Results and discussions}

First, the reaction of dimedone (3a), 4-chlorobenzaldehyde (1a), and malononitrile (2) (molar ratio: 1:1:1) was chosen as the model reaction. These were stirred at ambient temperature in ethanol. The reaction did not proceed to completion even after $2 \mathrm{~h}$ with only $20 \%$ of the product $\mathbf{4 a}$ was being isolated. In order to improve the yield and optimize the reaction conditions, the same reaction was carried out in the presence of cellulose-supported metal nanocomposite as a catalyst under similar conditions. Surprisingly, a significant improvement was observed and the yield of the product $4 \mathbf{a}$ was enhanced to $60 \%$ after stirring the reaction mixture for $1 \mathrm{~h}$. Next, we optimized the catalyst loading for this reaction and we noted that although the product could be formed with low catalyst loading (10 $\mathrm{mg} / \mathrm{mmol}$ of the reactant), the best outcome, in terms of yield and the reaction time, was obtained with $20 \mathrm{mg} / \mathrm{mmol}$ of cellulose-supported metal nanocomposite (Table 1). 
Table 1. Optimization of the amount of the catalyst. ${ }^{\text {a }}$

\begin{tabular}{|c|c|c|c|}
\hline Entry & Catalyst $(\mathrm{mg})$ & Time $(\mathrm{min})$ & Yield $^{\mathrm{b}}(\%)$ \\
\hline 1 & 0 & 120 & 20 \\
\hline 2 & 10 & 60 & 75 \\
\hline 3 & 20 & 20 & 96 \\
\hline 4 & 30 & 20 & 96 \\
\hline
\end{tabular}

${ }^{a}$ Reaction conditions: dimedone 3a $(1 \mathrm{mmol})$, 4-clorobenzaldehyde $1 \mathbf{a}(1 \mathrm{mmol})$, malononitrile 2 (1 mmol); catalyst: cellulose-supported nanocomposite; ethanol $(2 \mathrm{~mL}) .{ }^{\mathrm{b}}$ Isolated yields.

We also examined the effect of temperature on this reaction. It was found that the optimum temperature was $50{ }^{\circ} \mathrm{C}$ from the point of view of yield and reaction time. At higher temperatures, no further improvement on yield and reaction time was observed. On the other hand, the reaction did not proceed at room temperature. At $50{ }^{\circ} \mathrm{C}$, the reaction proceeded smoothly and almost complete conversion of the reagent was observed.

In order to generalize the optimum conditions, different derivatives of 2-amino-7,7dimethyl-5-oxo-5,6,7,8-tetrahydro-4H-benzo[b]pyran (4a-i) were prepared from the one-pot reaction mixture of aromatic aldehyde (1a-i), malononitrile (2) and dimedone (3a). The results are summarized in Table 2 . In addition to dimedone, 1,3-cyclohexadione (3b), was also examined for the synthesis of 2-amino-5-oxo-5,6,7,8-tetrahydro- $4 H$-benzo $[b]$ pyran (5ah). 
Table 2. Three-component synthesis of different 2-amino-5-oxo-5,6,7,8-tetrahydro-4H-benzo[b]pyrans (4a-5h) via condensation of various aldehydes (1), malononitrile (2), dimedone (3a) and 1,3-cyclohexadione (3b). ${ }^{\mathrm{a}}$

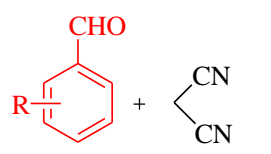

12
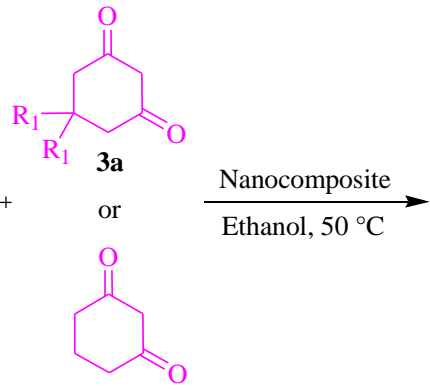

3b

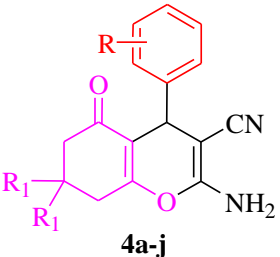<smiles>[R][X]c1ccccc1C1C(C#N)=C(N)OC2=C1C(=O)CCC2</smiles>

5a-h

\begin{tabular}{|c|c|c|c|c|c|c|}
\hline Entry & $\mathbf{R}$ & Product $^{b}$ & $\begin{array}{l}\text { Time } \\
(\mathrm{min})\end{array}$ & Yield $^{\mathrm{c}}(\%)$ & $\begin{array}{c}\text { Mp }\left({ }^{\circ} \mathrm{C}\right) \\
\text { Found }\end{array}$ & $\begin{array}{c}\left.\text { Mp ( }{ }^{\circ} \mathrm{C}\right) \\
\text { Reported }\end{array}$ \\
\hline 1 & $4-\mathrm{Cl}$ & $4 a$ & 20 & 96 & $213-216$ & $215-217^{[7 \mathrm{a}]}$ \\
\hline 2 & $4-\mathrm{Br}$ & $4 \mathrm{~b}$ & 25 & 94 & $215-218$ & $214-216^{[7 a]}$ \\
\hline 3 & 2,4-dichloro & $4 c$ & 30 & 94 & 191-193 & $192-194^{[10 c]}$ \\
\hline 4 & $4-\mathrm{NO}_{2}$ & $4 d$ & 20 & 95 & $180-183$ & $179-180^{[7 \mathrm{a}]}$ \\
\hline 5 & $3-\mathrm{NO}_{2}$ & $4 e$ & 25 & 95 & $212-215$ & $214-216^{[24]}$ \\
\hline 6 & $4-\mathrm{H}$ & $4 \mathrm{f}$ & 35 & 92 & $230-232$ & $234-235^{[10 c]}$ \\
\hline 7 & 4-Me & $4 \mathrm{~g}$ & 40 & 93 & $218-220$ & $220-222^{[11]}$ \\
\hline 8 & 4-Ome & $4 \mathrm{~h}$ & 40 & 90 & $198-200$ & $201-202^{[12]}$ \\
\hline 9 & 2-Furyl & $4 \mathrm{i}$ & 45 & 91 & $219-221$ & $220-223^{[11]}$ \\
\hline 10 & $4-\mathrm{Cl}$ & $5 a$ & 25 & 95 & $240-242$ & $241-243^{[13]}$ \\
\hline 11 & 2,4-dichloro & $5 b$ & 30 & 93 & $224-225$ & $224-225^{[14]}$ \\
\hline 12 & $4-\mathrm{NO}_{2}$ & $5 c$ & 25 & 95 & $237-238$ & $235-236^{[12]}$ \\
\hline 13 & $3-\mathrm{NO} 2$ & $5 d$ & 25 & 94 & $200-202$ & $201-202^{[12]}$ \\
\hline 14 & 4-H & $5 \mathrm{e}$ & 35 & 90 & 214-217 & $213-215^{[15]}$ \\
\hline 15 & 4-Me & $5 \mathrm{f}$ & 40 & 92 & $213-216$ & $214-216^{[15]}$ \\
\hline 16 & $4-\mathrm{OH}$ & $5 \mathrm{~g}$ & 40 & 90 & $235-238$ & $234-236^{[12]}$ \\
\hline 17 & 2-Furyl & $5 \mathrm{~h}$ & 45 & 90 & $198-200$ & $199-200^{[15]}$ \\
\hline
\end{tabular}

a Reaction conditions: aldehyde ( $1 \mathrm{mmol})$, malononitrile $(1 \mathrm{mmol})$, dimedone or 1,3-cyclohexadione (1 mmol); catalyst: nanocatalyst (20 mg); temp: $50{ }^{\circ} \mathrm{C}$; ethanol $(2 \mathrm{~mL})$.

${ }^{\mathrm{b}}$ All compounds are known and their structures were established from their spectral data and melting points as compared with authentic samples or literature values. ${ }^{c}$ The yields refer to isolated products. 
In order to demonstrate the scope of this new efficient methodology, the optimized reaction conditions were developed to another activated $\mathrm{C}$-H acidic1,3-diketone, 1,3-cyclopentadione (6a) and ethyl acetoacetate (6b), at the next stage. The results are summarized in Table $\mathbf{3}$. Again, almost quantitative yields were obtained for the desired products $(\mathbf{7 a - j})$ under the optimized conditions.

Table 3. Three-component synthesis of different 2-amino-5-oxo-4H-benzo[b]pyrans (7a-j) via condensation of various aldehydes (1), malononitrile (2), 1,3-cyclopentadione (6a) and ethyl acetoacetate (6b). ${ }^{\text {a }}$

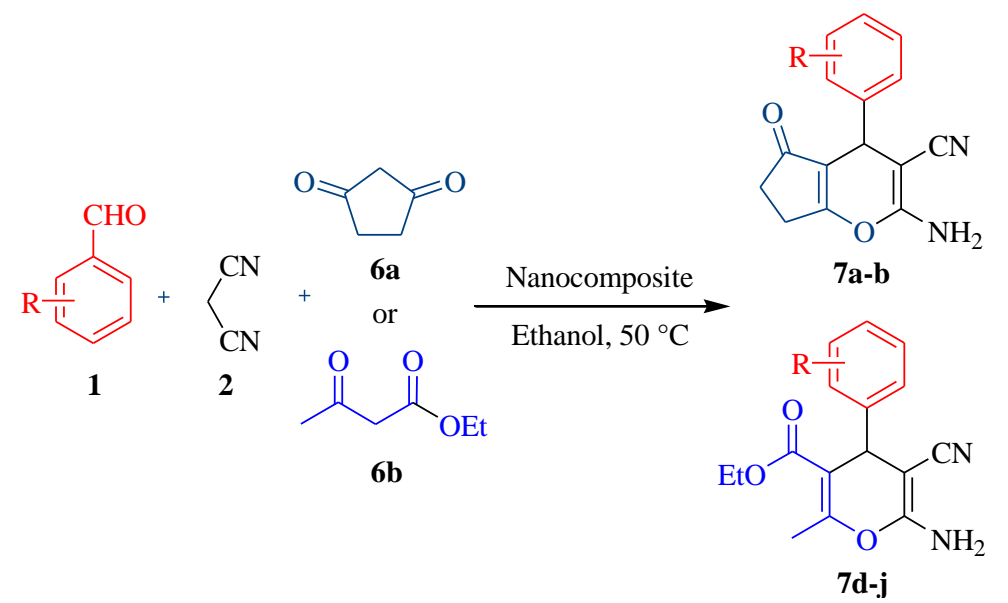

\begin{tabular}{|ccccccc|}
\hline Entry & $\mathbf{R}$ & Product $^{\mathbf{b}}$ & Time $(\mathbf{m i n})$ & Yield $^{\mathbf{c}}(\boldsymbol{\%})$ & $\mathbf{M p}\left({ }^{\circ} \mathbf{C}\right)$ Found & Mp $\left({ }^{\circ} \mathbf{C}\right)$ Reported \\
\hline 1 & $4-\mathrm{Cl}$ & $7 \mathrm{a}$ & 5 & 96 & $232-235$ & $234-237^{[16]}$ \\
2 & $4-\mathrm{Br}$ & $7 \mathrm{~b}$ & 5 & 94 & $212-214$ & $213-215^{[16]}$ \\
3 & $4-\mathrm{Cl}$ & $7 \mathrm{c}$ & 15 & 97 & $174-175$ & $172-174^{[17]}$ \\
4 & $4-\mathrm{Br}$ & $7 \mathrm{~d}$ & 15 & 97 & $262-265$ & $262-263^{[17]}$ \\
5 & $4-\mathrm{NO}_{2}$ & $7 \mathrm{e}$ & 15 & 96 & $175-177$ & $176-178^{[18]}$ \\
6 & $3-\mathrm{NO}_{2}$ & $7 \mathrm{f}$ & 15 & 96 & $224-226$ & $225^{[9]}$ \\
7 & $4-\mathrm{H}$ & $7 \mathrm{~g}$ & 20 & 92 & $187-189$ & $191-192^{[17]}$ \\
8 & $4-\mathrm{Me}$ & $7 \mathrm{~h}$ & 20 & 94 & $280-282$ & $280-282^{[17]}$ \\
9 & $4-\mathrm{OH}$ & $7 \mathrm{i}$ & 25 & 94 & $274-277$ & $274-275^{[17]}$ \\
10 & $2-\mathrm{Furyl}$ & $7 \mathrm{j}$ & 25 & 90 & $273-274$ & $274-275^{[17]}$ \\
\hline
\end{tabular}

${ }^{a}$ Reaction conditions: aldehyde ( $\left.1 \mathrm{mmol}\right)$, malononitrile $(1 \mathrm{mmol}), 1,3$-cyclopentadione or ethyl acetoacetate $(1 \mathrm{mmol})$; catalyst: nanocatalyst $(20 \mathrm{mg})$; temp: $50{ }^{\circ} \mathrm{C}$; ethanol $(2 \mathrm{~mL}) .{ }^{\mathrm{b}}$ All compounds are known and their structures were established from their spectral data and melting points as compared with authentic samples or literature values. ${ }^{\mathrm{c}}$ The yields refer to isolated products. 


\section{Conclusion}

In summary, cellulose-supported nanocomposite has been demonstrated as an efficient and environmentally benign catalyst for the multicomponent synthesis of 2-amino- $4 \mathrm{H}$ chromene derivatives. This protocol further demonstrates in avoiding hazardous organic solvents and toxic catalysts, reusability of the catalyst, increasing yields, reducing reaction time, and streamlining high-throughput chemistry. The mildness, experimental convenience and compatibility are also the key advantages which make this method a superior alternative to the existing protocols.

\section{Acknowledgements}

The authors gratefully acknowledge the partial support from the Research Council of the Iran University of Science and Technology.

\section{References}

[1] J. Zhu, H. Bienaymé. Multicomponent Reactions. Wiley-VCH: Weinheim, 2005.

[2] L. Weber. Drug Disc. Today 2002, 7,143.

[3] N. D. McClenaghan, R. Passalacqu, F. Loiseau, S. Campagna, B. Verheyde, A. W. Hameurlaine. J. Am. Chem. Soc. 2003, 125, 5356.

[4] M. G. Dekamin, M. Eslami and A. Maleki. Tetrahedron, 2013, 69, 1074-1085.

[5] (a) B. S. Kumar, N. Shrinvasulu, R. H. Udupi, B. Rajitha, Y. T. Reddy, P. N. Reddy and P. S. Kumar, J. Heterocyclic Chem., 2006, 43, 1691-1693; (b) H. Eshghi, S. Damavandi and G. H. Zohuri, Synth. Reac. Inorg. Met., 2011, 41, 1067-1073; (c) M. M. Heravi, B. Baghernejad and H. A. Oskooie, J. Chin. Chem. Soc., 2008, 55, 659-662; (d) S. M. Baghbanian, N. Rezaeiand H. Tashakorian, Green Chem., 2013, 15, 3446-3458; (e) S. K. Kundu, J. Mondal and A. Bhaumik, Dalton Trans., 2013, 42, 10515-10524.

[6] (a) J. K. Rajput and G. Kaur, Catal. Sci. Technol., 2014, 4, 142-151; (b) J. Albadi, A. Razeghi, A. Mansournezhad and Z. Azarian, J. Nanostruct. Chem., 2013, 3, 85-89; (c) S. 
R. Kale, S. S. Kahandal, A. S. Burange, M. B. Gawande and R. V. Jayaram, Catal. Sci. Technol., 2013, 3, 2050-2056; (d) M. P. Surpur, S. Kshirsagar and S. Samant, Tetrahedron Lett., 2009, 50, 719-722; (e) R. Maggi, R. Balliniand G. Sartori, Tetrahedron Lett., 2004, 45, 2297-2299.

[7] (a) S. Balalaie, M. Bararjanian, A. M. Amani and B. Movassagh, Synlett, 2006, 2, 263266; (b) M. Al-Matar, K. D. Khalil, H. Meier, H. Kolshorn and M. H. Elnagdi, Arkivoc, 2008, 16, 288-301; (c) T. A. Khan, M. Lal, S. Ali and M. M. Khan, Tetrahedron Lett., 2011, 52, 5327-5332; (d) M. M. Heravi, M. Zakeri and N. Mohammadi, Chin. J. Chem., 2011, 29, 1163-1166.

[8] (a) S. Gao, C. Hsuan, C. Tseng and C. F. Yao, Tetrahedron, 2008, 64, 9143-9149; (b)T. S. Jin, J. S. Zhang, L. B. Liu, A. Q. Wang and T. S. Li, Synth. Commun., 2006, 36, 20092015; (c) C. Lu, X. J. Huang, Y. Q. Li, M. Y. Zhou and W. Zheng, Monatsh. Chem., 2009, 140, 45-47; (d) A. Hasaninejad, M. Shekouhy, N. Golzar, A. Zare and M. M. Doroodmand, Appl. Catal. A: Gen., 2011, 402, 11-22.

[9] J. C. Xu, W. M. Li, H. Zheng, Y. F. Lai and P. F. Zhang, Tetrahedron, 2011, 67, 95829587.

[10] (a) S. Javanshir, S. Sharifi, A. Maleki, B. Sohrabi, M. Kiasadegh, J. Phys. Org. Chem. 2014 , 27, 589-596; (b) M. Safari, S. Javanshir, M. G. Dekamin, Sci. Iran., 2013, 20, 742-747; (c) B. Kazemi, S. Javanshir, A. Maleki, M. Safari, H. R. Khavasi Tetrahedron Lett., 2012 , 51 , 6977-6981.

[11] A. A. Shestopalov, L. A. Rodinovskaya, V. P. Litvinov, Russ. Bull. Chem., 2004, 53, 724-725.

[12] F. M. Abdel-Galil, Chem. Lett., 1982, 1123-1126.

[13] M. Kazemzad, A. A. Yuzbashi, S. Balalaie and M. Bararjanian, Synth. React. Inorg. M., 2011, 41, 1182-1187

[14] C. Talotta, C. Gaeta, P. Neri, Org. lett., 2012, 14, 3104-3107.

[15] A. Abdollahi, F. Nezampour, Reaction Kinetics, Mechanisms and Catalysis., 2013, $108,213-229$. 
[16] Y. M. Litvinov and A. M. Shestopalov, in Advances in Heterocyclic Chemistry, ed. A. R. Katritzky, Elsevier, Amsterdam, 2011, 103, 175-260.

[17] L. Rong, X. Li, H. Wang, D. Shi, Sh. Tu and Q. Zhuang, Synth. Commun., 2006, 36, 2363-2369.

[18] A. Patra and T. J. Mahapatra, J. Chem. Res., 2010, 689-693. 